\title{
Subsistencia, dieta, salud y enfermedad en el pasado: del paradigma osteológico a la era molecular en Colombia
}

research paper

\section{Subsistence, diet, health and disease in past: from the osteological paradox to the molecular era in Colombia}

\author{
María Antonieta Corcione ${ }^{1}$ \\ Universidad de los Andes \\ (iD) https://orcid.org/0000-0002-3509-5519
}

\author{
Freddy Rodríguez ${ }^{2}$ \\ Universidad de los Andes \\ https://orcid.org/0000-0001-9709-4258
}

Resumen: En las últimas décadas, la bioarqueología colombiana ha tenido un desarrollo prominente tanto en la aplicación de nuevas técnicas como en la maduración de las conceptualizaciones teóricas en líneas temáticas sobre la subsistencia, la dieta, la salud y la enfermedad de las poblaciones prehispánicas que habitaron el territorio nacional. A diferentes escalas de análisis, los investigadores colombianos han resuelto interrogantes desde perspectivas multidisciplinares como la ecológica, la evolutiva y la biocultural utilizando cada vez más técnicas radiológicas, histológicas y moleculares para la consecución de información. Este artículo de revisión tuvo como objetivo realizar un barrido de las investigaciones generadas en torno a los debates bioarqueológicos sobre adaptación al medio, migración y colonización de nuevos nichos, dieta, marcadores de actividad y condiciones de vida, principalmente. Sin que sea una exploración exhaustiva de la gran producción investigativa en el país, esta revisión ha permitido comprender los nuevos panoramas analíticos que se están generando entre los antropólogos de las diferentes regiones y de esta forma realizar una reflexión acerca de las nuevas sinergias que se promueven en la ciencia bioarqueológica colombiana.

Palabras clave: bioarqueología; dieta; paleopatología; subsistencia y arqueología molecular; Colombia.

Recibido: 31/01/2019 | Aceptado: 24/10/2019 | Disponible en línea: 15/12/2019

Cómo citar este artículo: Corcione, M. A. y Rodríguez, F. (2020). Subsistencia, dieta, salud y enfermedad en el pasado: del paradigma osteológico a la era molecular en Colombia. Jangwa Pana, 19(1), 23 - 44. Doi: https://doi.org/10.21676/16574923.3355

\begin{abstract}
In recent decades, Colombian bioarchaeology has had a prominent development both in the application of new techniques and in the maturation of the theoretical conceptualizations in thematic lines on subsistence, diet and health and disease of the pre-Hispanic populations that inhabited the national territory. At different scales of analysis, Colombian researchers have solved questions from multidisciplinary perspectives such as ecological, evolutionary and biocultural using increasingly, radiological, histological and molecular techniques for the acquisition of information. This review seeks to take a look of the research generated around the bioarchaeological debates on adaptation to the environment, migration and colonization of new niches, diet, markers of activity and living conditions. Without being an exhaustive exploration of the great research production in Colombia, this review has made it possible to understand the new analytical
\end{abstract}

\footnotetext{
${ }^{1}$ Correo electrónico: ma.corcione45@uniandes.edu.co.

${ }^{2}$ Correo electrónico: f.rodriguez98@ uniandes.edu.co.
} 
scenarios that are being generated among the anthropologists of the different regions and in this way to reflect on the new synergies that are promoted in bioarchaeological science.

Key words: bioarchaeology; diet; paleopathology; subsistence and molecular archaeology; Colombia.

\section{Introducción}

El presente artículo de revisión tiene por objeto brindar un panorama general de los aportes más relevantes de la investigación bioarqueológica en Colombia, centrados en la relación entre las estrategias de subsistencia, la dieta y el estado de salud-enfermedad de las poblaciones prehispánicas a partir del estudio de restos óseos humanos, dentales y momificados. En este sentido, más que una descripción y análisis exhaustivo de la producción científica en el área de la bioarqueología colombiana, el texto se ha centrado en la identificación crítica de algunas investigaciones realizadas a lo largo del territorio nacional para exponer los avances teóricos, nuevas propuestas a nivel metodológico y, finalmente, las contribuciones a diferentes escalas de análisis sobre el tema en cuestión.

Considerados como ecofactos ${ }^{3}$, los restos óseos tienen una situación privilegiada en la arqueología. Esto se debe, especialmente, a los avances a niveles teórico y metodológico derivados de las propuestas de la arqueología procesual, que dieron paso a finales de los años setenta en los Estados Unidos al desarrollo de la bioarqueología ${ }^{4}$.

A través del estudio de los restos esqueléticos, dentales y momificados, la bioarqueología busca reconstruir el comportamiento de las sociedades del pasado, generando inferencias acerca de las condiciones de vida de las poblaciones, los patrones de dieta y nutrición, la actividad física, la salud, la enfermedad, la demografía y las interacciones genéticas (Larsen, 2015). Con ese fin, emplea en gran medida como marco de referencia la ecología humana, el enfoque biocultural y la arqueología evolutiva, en un intento por integrar los datos y las teorías de la arqueología, la antropología biológica, la historia, la antropología cultural, las ciencias médicas, la geografía y afines (Buzon, 2012).

Adicionalmente, como parte del registro arqueológico, los restos óseos - y por tanto el tejido óseo- se ven afectados por procesos tafonómicos post mortem: deposicionales y posdeposicionales (McKee, 2010; Suby, 2012). Sin embargo, al ser sistemas abiertos, dinámicos, históricos y adaptativos, los huesos también se ven continuamente impactados, a lo largo de la vida del individuo, en su proceso de desarrollo y crecimiento, como respuesta a diferentes presiones y estímulos producidos por agentes intrínsecos (influencia genética, metabólica, endocrina, etc.) y extrínsecos (contexto socioambiental) (Larsen, 2001b; Luna, 2006), "dejando huellas o evidencias osteobiográficas" (Scott, Willey y Connor, 1998, p. 361).

\footnotetext{
${ }^{3}$ Como han demostrado Graham Clark y otros pioneros del enfoque ecológico, existe toda una categoría de restos orgánicos y medioambientales no artefactuales llamados, en ocasiones, "ecofactos" (Renfrew y Bahn, 2011, p. 51-52).

${ }^{4}$ La definición de bioarqueología en Estados Unidos hace referencia exclusivamente al estudio de restos óseos humanos, mientras que en el Reino Unido refiere al análisis de restos osteoarqueológicos, es decir, la combinación del estudio de restos óseos humanos y animales. En Colombia, los estudios bioarqueológicos se vinculan a la vertiente norteamericana. El desarrollo de esta ciencia en el país se establece a partir del vínculo que tiene la antropología con la escuela boasiana y el desarrollo de la antropología en cuatro ramas. Así, en la década de los noventa e inicios del nuevo siglo se da la transformación de lo que se conoce como antropología física (una de las ramas propuestas por Fran Boas) en bioarqueología.

${ }^{5}$ El término "osteobiografía" se define como la historia de vida de una persona documentada a través de sus restos óseos (Neves, 1984; Saul, 1976).
} 
Estas evidencias pueden ser estudiadas en dos niveles (macroscópico y microscópico), de manera multimodal (osteología, rayos X, TC, patologías dentales, isótopos estables, etc.) y a diferentes escalas de análisis (individual, intrapoblacional, interpoblacional, local, regional, etc.). El objetivo es aproximarse a la comprensión de las dinámicas del trinomio individuo-ambiente-comportamiento (Goodman 1998; Goodman y Leatherman, 1998; Goodman, Swedlund, Brooke y Armelagos, 1988). Es así como paulatinamente se ha ido avanzando en la resolución de múltiples interrogantes arqueológicos respecto a los procesos de migración y dispersión de grupos humanos a través de un territorio, las condiciones demográficas necesarias para colonizar nuevos espacios, el papel del medio ambiente en el deterioro de la calidad de vida, el impacto de los cambios de la estrategia de subsistencia en las poblaciones, las transformaciones o continuidades de los patrones alimenticios, la relación entre el estatus social, los hábitos de trabajo y el consumo de alimentos, así como el estado de salud-enfermedad de las poblaciones en diferentes ambientes.

Para el caso colombiano, las tendencias en la bioantropología ${ }^{6}$ no han estado alejadas de este desarrollo, dadas las recientes propuestas teóricas y metodológicas que han enriquecido este campo del conocimiento tanto a nivel de poblaciones actuales como de las del pasado, poniendo de manifiesto la necesidad de una mayor integración de las perspectivas bioculturales (Delgado y Rosique, 2012; Rojas, 2014; Tabares, Rosique y Delgado-Burbano, 2012). En este sentido, una tarea pendiente desde la bioarqueología nacional consiste en examinar críticamente los presupuestos e inferencias alcanzados hasta el momento respecto a la relación entre las estrategias de subsistencia, la dieta y el estado de salud-enfermedad, examinando particularmente la calidad de la información que ha acompañado la conformación de los esquemas de desarrollo sociocultural dentro de la arqueología colombiana.

Lo anterior significa, también, abordar los problemas de orden escalar entre los interrogantes de investigación y las estrategias de análisis empleadas para la construcción de modelos que nutren la base de los esquemas mencionados (Jaramillo, 2012). Esto se direcciona hacia una discusión relacionada con la paradoja osteológica ${ }^{7}$ (DeWhite y Stojanowski, 2015; Wood, Milner, Harpending y Weiss, 1992) —en términos de la revisión de las interpretaciones y de los presupuestos hechos en el pasado sobre diferentes colecciones óseas-, de las nuevas perspectivas teóricas y del desarrollo de nuevos métodos de investigación (osteológicos, dentales, radiológicos, bioquímicos, moleculares).

\footnotetext{
${ }^{6}$ De acuerdo con Delgado y Rosique (2012), las tendencias actuales de la bioantropología en Colombia son: antropología y diversidad genética, antropología de la nutrición, estudios bioarqueológicos de grupos prehispánicos, cuestiones metodológicas de genética de poblaciones y tendencias, e historia de la bioantropología en Colombia.

${ }^{7}$ En 1992, Wood et al. propusieron la paradoja osteológica para poner de manifiesto dos consideraciones críticas a la hora de realizar inferencias bioarqueológicas de poblaciones esqueléticas sin estacionariedad demográfica: la fragilidad heterogénea y la mortalidad selectiva. La primera se refiere a la susceptibilidad que presentan algunos individuos de enfermar o morir debido al posible acceso a recursos alimenticios, lo que derivaría en un aumento de la vulnerabilidad para ciertos individuos a padecimientos por carencias nutricionales o de tipo infeccioso, principalmente. Esta fragilidad heterogénea deriva en la mortalidad selectiva en la población (Corcione, 2016). Por lo tanto, nunca se tendrá una muestra representativa de todos los individuos que estuvieron en riesgo de enfermarse o de morir a una edad determinada, sino solo de aquellos que murieron a esa edad. Las consideraciones críticas se resumen en: a peores esqueletos, mejor estado de salud (Civera, 2005).
} 
En consecuencia, resultan pertinentes los argumentos que refieren la necesidad de adelantar estudios más allá de la escala local y de usar múltiples estrategias de investigación, lo cual daría una perspectiva del estilo de vida de los grupos humanos que habitaron distintos territorios y periodos, así como de las posibles variables que modularon los procesos de complejización en el territorio colombiano (Cárdenas, 2002; Gómez, 2011).

Valdría la pena entonces volver la mirada a los modelos de análisis de las teorías de las transiciones nutricionales (Grigg, 1995), las transiciones demográficas (Bongaarts, 2009) y las transiciones epidemiológicas (Armelagos y Barnes, 1999; Armelagos, Brown y Turner 2005; Barnes, Armelagos y Morreale, 1999; Cohen y Crane-Kramer, 2003, entre otros). Estas son propuestas que, en otros contextos, han permitido mejorar la comprensión de las causas y las consecuencias de las modificaciones en los patrones dietarios, los aumentos poblacionales y el desarrollo e impacto de las enfermedades en el pasado (por ejemplo, BocquetAppel y Bar-Yosef, 2008).

\section{Discusión}

\section{Desarrollo histórico de los análisis bioarqueológicos en Colombia}

En los inicios de la disciplina arqueológica en Colombia, los restos óseos humanos hacían parte del acervo de antigüedades como simples curiosidades o como objetos válidos de ser registrados y descritos por viajeros, naturalistas y diferentes estudiosos interesados en las $\operatorname{razas}^{8}$ y en el origen del hombre americano. Para la década de 1940, los trabajos pioneros de Eliécer Silva Celis sobre diferentes contextos funerarios del territorio nacional, complementados con datos etnohistóricos y etnográficos de grupos indígenas modernos, así como los detallados análisis bioantropológicos y osteométricos y de las prácticas de momificación -enfocados principalmente en poblaciones prehispánicas del altiplano cundiboyacense (Van der Hammen y Correal 1963; 1978)_, aportaron datos interesantes a la discusión acerca del origen y las relaciones biológicas entre los grupos de esta región, y brindaron la posibilidad de indagar acerca de las condiciones de salud de los individuos (Rodríguez Cuenca, 2001).

Ya para los años sesenta y setenta, el panorama arqueológico comienza a comprender el pasado como una cuestión regional, lo cual permite mostrar por primera vez cambios adaptativos a lo largo del tiempo. Los hallazgos en los abrigos rocosos de Sueva, Nemocón (Correal, 1979), El Abra y Tequendama (Correal y Van der Hammen, 1977) y el sitio a cielo abierto de Aguazuque (Correal, 1990), en la sabana de Bogotá, constituyeron contextos arqueológicos que aportaron nuevos datos a la discusión sobre la relación entre características ambientales y el tránsito a nuevas formas adaptativas en las poblaciones más tempranas conocidas hasta el momento en el territorio nacional. Así, en palabras de Gómez (2011),

\footnotetext{
${ }^{8}$ En la actualidad la noción de raza está ausente de los primeros registros históricos y geográficos y se desliga del concepto de nación y sus consecuentes usos políticos. En el campo de la antropología biológica, a partir de la mitad del siglo XX el concepto de raza dio un salto conceptual. Aquí se empiezan a incorporar conceptos que incluyen caracteres genéticos a los conceptos clasificatorios fenotípicos de especie humana (Perosino, 2005). El debate entre antropólogos biológicos que defienden o rechazan el concepto de raza y su utilización sigue en pie. Para ampliar la discusión de la actual noción de raza pueden revisarse los trabajos de Pérez Lezaun y Bertranpetit (2000), Rodero y Herrera (2000), Wade (2002), entre otros.
} 
la antropología biológica adquiere durante las décadas de los 70 y 80 una perspectiva multidisciplinaria con claros intereses hacia las dinámicas adaptativas y evolutivas de las poblaciones humanas, y un grado de profundidad temporal, dado por las investigaciones con restos óseos humanos provenientes de excavaciones ( $\mathrm{p}$. 193).

Como parte central de estos cuestionamientos adaptativos sobre las poblaciones, y enmarcados esencialmente bajo la teoría de la ecología humana ${ }^{9}$, los análisis de restos faunísticos y arqueobotánicos se convirtieron en factores fundamentales para comprender la adaptación de los grupos prehispánicos a diversos ambientes y el aprovechamiento de diferentes recursos como parte de la dieta, asociándolos posteriormente a los indicadores óseos de estrés, a la aparición o ausencia de determinadas patologías, a la actividad física y al impacto de la presión ambiental ejercida en los individuos. Desde la óptica de la ecología humana, se asumió que la "salud y enfermedad son medidas para comprobar la efectividad con que los grupos humanos combinan recursos biológicos y culturales para adaptarse a sus ambientes" (Lieben, 1973, p. 1031).

Si bien el alimento es fundamental para el ser humano dado que proporciona los nutrientes necesarios para el crecimiento, el desarrollo y otros procesos fisiológicos (Larsen, 2001a), desde el punto de vista arqueológico y bioarqueológico debe entenderse a partir de varias perspectivas. La primera tiene que ver con la apropiación de recursos y la forma como estos son transformados para el consumo humano, comprendiendo así mismo que los patrones de producción y consumo de alimentos implican múltiples esferas, tales como la ideológica, la religiosa y la política, o cómo el acceso diferencial estuvo ligado al estatus de los individuos (Goody, 1995; Messer, 1995). Una segunda perspectiva refiere a los espacios de vida doméstica/áreas de actividad donde se materializan los sistemas alimentarios, sin que esto implique dejar de lado que el hecho alimentario no se restringe al lugar de preparación/consumo/descarte de desechos (Jaramillo, 2012). La tercera perspectiva corresponde a la respuesta que presenta el organismo ante diferentes fenómenos de carencia o consumo excesivo y a los problemas derivados del estrés ${ }^{10}$, las influencias ambientales y el modo y el estilo de vida de los individuos en un grupo social (Huss-Ashmore, Goodman y Armelagos, 1982; Klaus, 2014, entre otros).

Dentro de estas nuevas perspectivas, entre la década de los ochenta y la década de los noventa en el país, como componente fundamental de la cultura, el estudio de la dieta se vuelve fundamental porque permite abordar las estrategias de subsistencia, los tipos de alimentos consumidos, el desarrollo económico, las redes comerciales, los flujos migratorios, la adaptación a cambios climáticos y medioambientales y su relación con variables culturales (estatus o jerarquía social) y demográficas (el sexo y la edad). De igual modo se empieza a establecer la relación con diferentes enfermedades asociadas a la nutrición, crecimiento y desarrollo (Lanata, Martino, Osellac y García-Herbstd, 2008).

\footnotetext{
${ }^{9}$ El término "adaptación” se refiere al carácter diseñado para cumplir una función por selección natural. En cuanto a "exaptación", se entiende como el carácter diseñado para una determinada función que es cooptado para cumplir otra o que es no adaptativo por no ser originado por selección natural. El concepto biológico de adaptación, descrito como un tipo de relación entre organismos, es fundamental en la teoría evolutiva. Ahora bien, siendo polisémico, puede referirse tanto a un proceso como a un rasgo o a un estado (Scheinsohn, 2011).

${ }^{10}$ El estrés se ha entendido como una condición externa que altera el organismo, el cual es capaz de responder con una reacción fisiológica, ya sea favorable o desfavorable (Gómez, 2012). Va dirigido a las consecuencias de eventos disruptivos sobre los individuos y las poblaciones (Goodman y Leatherman, 1998).
} 
Este interés conceptual y la integración de diferentes técnicas y metodologías multidisciplinares a los estudios de series óseas arqueológicas configuraron el panorama de la bioarqueología colombiana en los años ochenta, la cual se centró en entender la transición entre sociedades de cazadores-recolectores a grupos sedentarios-agrícolas y cómo la adaptabilidad a diversos ambientes y la introducción de la agricultura tuvieron efecto en la adquisición y el consumo de alimentos para la subsistencia, además de las repercusiones de estos cambios socioambientales en el estado de salud de los individuos y las comunidades.

A partir de la década de los noventa, las investigaciones relacionadas con el estudio de la dieta e interpretación de los hábitos alimenticios de las sociedades prehispánicas en Colombia siguieron con el mismo enfoque teórico de la década anterior, centrándose en las siguientes aproximaciones metodológicas: a) el análisis de artefactos líticos usados para la producción, obtención y modificación de los alimentos (Ardila, 1984; Correal, 1990; Correal y Pinto, 1983; Gnecco, 1994; 1997; 2000; Gnecco y Salgado 1989; López, 1989; 1994; 1999; Oyuela-Caycedo, 1996; Salgado, 1989); b) el estudio de macro y microrrestos botánicos (Aceituno y Lalinde, 2011; Aceituno y Loaiza, 2014; Cavelier, Rodríguez, Herrar, Morcote y Mora, 1995; Gnecco y Mora, 1997; Mora, Herrera, Cavelier y Rodríguez, 1991; Morcote, 2008; Morcote y Cavelier, 1999; Posada, 2014); c) el estudio de restos de fauna (Correal, 1981a; 1981b; Enciso, 1996; 1993; Peña, 2013; Ramos, 2002; Ramos y Archila, 2008); d) el análisis químico en muestras cerámicas asociadas a contextos domésticos (unidades de vivienda) (Galindo, Castro y Henderson, 2013); e) el análisis de polen y paleosuelos (Andrade, 1986; Cavelier, Mora y Herrera, 1990; Eden, Bray, Herrera y McEwan, 1984; Herrera, 1981; 1985); f) el análisis de restos óseos humanos, particularmente a través del estudio de los patrones de micro y macrodesgaste dental usando una perspectiva morfofuncional (Rodríguez, 2009; 2013) y de los fitolitos presentes en el cálculo dental (Gil, 2011; Parra, 2001), y g) el análisis de isótopos estables ${ }^{11}$ (Aristizábal, 2016; Cadena, 2010; Cárdenas, 1995; 1996; 1998; 2002; Castillo, 1998; Delgado Burbano, 2007; Delgado, Langebaek, Aristizábal, Tykot y Johnson, 2014; Osorio, 2012; Van der Hammen, Correal y Van Klinken, 1990).

En lo que respecta a las aproximaciones sobre el poblamiento temprano y la dispersión de los grupos humanos en el norte de Suramérica y sus estrategias de subsistencia, por décadas se asumió que las poblaciones de finales del Pleistoceno y del Holoceno temprano correspondían a grupos altamente móviles, con un estilo de vida basado en la caza y recolección como una forma económica previa a los grupos agrícolas, quienes eran transformadores activos de los ecosistemas (Delgado Burbano, 2017). No obstante, recientes avances han brindado un panorama distinto, sugiriendo que estos grupos ya estaban impactando y alterando el ecosistema desde finales del Pleistoceno mediante diferentes prácticas de manipulación de recursos para aumentar su productividad (Aceituno, 2001a; 2001b; 2002; Castillo y Aceituno, 2000; 2006; Gnecco y Aceituno, 2004; Gnecco y Mora, 1997; Gnecco y Salgado, 1989; López, 1999; Mora y Gnecco, 2002; Santos, Monsalve y Correa, 2014).

Al respecto, Aceituno, Loaiza, Delgado-Burbano y Barrientos (2013) hacen un valioso aporte al presentar una revisión general de los datos paleoambientales y arqueológicos

\footnotetext{
${ }^{11}$ La relación entre elementos químicos como los isótopos de carbono y nitrógeno y los elementos traza como el estroncio y el bario (Burton y Wright, 1995) proporciona información sobre la dieta. En los huesos queda registrada la diferencia de esta relación, que indica el tipo de plantas y la cantidad de alimentos de origen acuático consumidos.
} 
relacionados con la transición Pleistoceno-Holoceno y con el periodo paleoindio (temporalidad) del norte de Suramérica, enfocándose esencialmente en el estado del conocimiento actual sobre las estrategias adaptativas de los primeros grupos de cazadores recolectores del territorio colombiano. El análisis combinado de la localización geográfica de los sitios arqueológicos tempranos reportados en cinco regiones - cuenca media del río Cauca, cuenca del Magdalena, cuenca del río Calima, Porce medio y sabana de Bogotá-, de las fechas de radiocarbono y de las características de los conjuntos líticos les permite inferir que la diversidad en la tradición lítica puede ser el resultado de estrategias de adaptación alternas que buscan hacer frente a las condiciones cambiantes de la transición entre el Pleistoceno-Holoceno, o que dicha variabilidad estaría relacionada con el encuentro en un corto periodo de tiempo de diferentes poblaciones que ingresaron a Suramérica, lo cual difiere del modelo clásico de poblamiento temprano por un único stock poblacional o grupo fundador (Rodríguez Cuenca, 1999; 2001; 2007; Rodríguez Cuenca y Vargas, 2010).

Adicionalmente, Aceituno et al. (2013) arguyen la posibilidad de una expansión territorial en los valles subandinos del norte de los Andes y la aparición de estrategias de adaptación innovadoras que coincidiría con el aumento de los bosques tropicales, resaltando el hecho de la alteración de los ecosistemas locales y el valor de las plantas en las estrategias de subsistencia de los primeros grupos humanos, como preámbulo del origen del cultivo de plantas.

Las preguntas acerca del poblamiento, la dispersión y las migraciones en el territorio nacional de grupos humanos han sido una constante en la agenda investigativa bioarqueológica. Siguiendo con esta línea, se destacan los trabajos de Delgado Burbano (2012a; 2012b), los cuales, a diferentes escalas de análisis y usando métodos morfométricos, le permiten proponer un modelo para explicar el proceso de poblamiento temprano para Colombia y la sabana de Bogotá, la subsecuente evolución poblacional y la diversidad biocultural a lo largo del Holoceno. El autor asocia la alta divergencia morfológica encontrada entre los grupos de cazadores recolectores y los de agricultores a cambios en la estrategia de subsistencia, mientras que relaciona la relativa homogeneidad morfológica de los grupos agricultores con contactos poblacionales a gran escala, el aumento demográfico y la dispersión de la agricultura.

A escala regional — para la sabana de Bogotá-, Delgado Burbano (2012b) encuentra un patrón similar que respalda un modelo de discontinuidad poblacional (PDM). Esto deja entrever eventos de extinción/dispersión de la población y la llegada de nuevos grupos del valle medio del Magdalena y sus alrededores, y posteriormente el arribo de nuevas poblaciones con una estrategia de subsistencia asociada a la agricultura. A partir de estos procesos, este investigador rechaza la hipótesis del poblamiento temprano por un único stock o única población fundadora y el modelo de cambio microevolutivo gradual a partir de esta.

Mientras que la información arqueológica disponible ha identificado desde el Holoceno temprano la manipulación de plantas para el caso de la cordillera Central, la costa Caribe colombiana muestra evidencias de un desarrollo temprano en la producción de alimentos (donde el procesamiento de yuca es inferido indirectamente a partir de evidencia lítica y cerámica) y de cerámica, así como de un proceso de sedentarización de los grupos a finales del IV milenio a. C. (Oyuela-Caicedo, 1996; Rodríguez Cuenca, 2011). 
Sin embargo, Langebaek (1994) señala que es probable que los grupos no practicaran la agricultura como tal y que, más bien, alimentos como la yuca fueran un complemento a la dieta, basada fundamentalmente en consumo de moluscos (que dio origen a la conformación de concheros), la pesca, la caza y la recolección. Esto sugiere entonces la incorporación de múltiples estrategias de apropiación de diversos recursos, anteriores a la adopción de la agricultura (Langebaek, 2011). De todos modos, aún persiste un vacío en el conocimiento arqueológico relacionado con la importancia de los econichos correspondientes a manglares para la dieta de las poblaciones costeras (Archila, 1993), pero sí se ha inferido desde la óptica epidemiológica que los grupos costeros parecen haber estado más influenciados por parasitosis intestinales, las cuales repercutieron $a$ posteriori en la aparición de cuadros de anemias, caracterizados por presencia esquelética de hiperostosis porótica y criba orbitaria (Correal, 1990; Rodríguez Cuenca, 2011).

Ahora bien, enmarcada en la concepción lo que comemos es lo que somos, se ha ido delineando una relación directa entre los estados de salud y la nutrición en los estudios paleopatológicos ${ }^{12}$ para las muestras excavadas en el país (Boada, 1988; Correal, 1996). Ocurre, no obstante, que no todas las patologías tienen una causa directamente asociada con la alimentación, ya sea en exceso o carencial, ni con la nutrición, tanto en estados de malnutrición como de desnutrición. Ya que el sistema esquelético presenta respuestas limitadas ante los agentes estresores que lo afectan, los factores indirectos, tales como la estatura en edad adulta, han sido usados para inferir condiciones de salud en la edad infantil y juvenil en individuos de diversas poblaciones colombianas, lo cual ha permitido suponer acerca de la buena o mala salud de las poblaciones prehispánicas, dejando de lado las discusiones planteadas por la paradoja osteológica (Cárdenas, 1990; Langebaek et al., 2011; Rodríguez Cuenca, 1999). De igual manera, los análisis de patología dental y del sistema masticatorio, respecto a los componentes de la dieta, han tenido un papel importante en la determinación del estado de salud en individuos adultos (Langsjoen, 1998), aislando el sistema masticatorio de la homeostasis del resto de sistemas del cuerpo humano.

El análisis de las patologías dentales, posibles de identificar debido a las buenas características de conservación de las piezas, ha tenido un desarrollo continuo en Colombia en lo que se ha denominado antropología dental. Los estudios sobre crecimiento (maduración dental) y degeneración (desgaste) de los tejidos dentales también son considerados como registros directos de procesos patológicos asociados a las condiciones alimenticias y al desarrollo tecnológico en la preparación de alimentos de los grupos antiguos (Rodríguez, 2005). Los rasgos dentales patológicos asociados indirectamente a la alimentación, tales como presencia de caries, hipoplasias de esmalte, infecciones en el tejido óseo y pérdida ante mortem de piezas, han sido usados como marcadores biológicos para inferir de manera directa las condiciones de salud de las poblaciones, sugiriendo por ejemplo un tipo de dieta alta en hidratos de carbono (otorgada principalmente por el alto consumo de maíz) o periodos de desnutrición durante la infancia (Cárdenas, 2002; Rodríguez Cuenca, 1987; 1999; 2001; 2006; Sotomayor, 2007).

12 La paleopatología hace parte central de los análisis bioarqueológicos, permitiendo desarrollar interpretaciones completas e integrales de la salud y la enfermedad de las sociedades del pasado para inferir condiciones de vida (Buzon, 2012). 
Ahora bien, las características registradas en el material óseo como rasgos patológicos asociados a estados anémicos y a la afectación de enfermedades metabólicas han estado fuera de la discusión bioarqueológica en el contexto colombiano para cualquier enfoque teórico. Esto puede estar relacionado con la poca representatividad de las muestras óseas por la presunción de que las condiciones ambientales y adaptativas otorgadas por las regiones tropicales no permiten que las enfermedades carenciales se produzcan, ya sea por la ubicación del territorio en la zona ecuatorial y la abundancia de frutos ricos en vitaminas, o por las prácticas de producción agrícola de los grupos de montaña en la utilización de diferentes pisos térmicos para acceder a diversidad de alimentos a lo largo de periodos de cosecha, hecho que impediría el padecimiento de periodos de poca producción agrícola y, por ende, habría poca afectación de patologías relacionadas con estados carenciales de alimento (Cárdenas, 1990; Corcione, 2016; Langebaek, 1990).

De forma particular, los indicadores de dieta, salud y demografía para los grupos de cazadores recolectores durante el Holoceno temprano (por lo menos para la sabana de Bogotá) parecen mostrar una tendencia manifestada por una alta expectativa de vida, disposición al desarrollo de enfermedades articulares (EAD), elevada atrición dental, nula o excepcional presencia de caries, así como una baja predominancia de agentes infecciosos. Para esta misma región, las evidencias de la manipulación de plantas y el incremento en el consumo de vegetales en grupos hortícolas comparadas con otras regiones aparecen tardíamente en el registro arqueológico (alrededor del II milenio a. C.), junto con un crecimiento demográfico y el inicio de una vida sedentaria, acompañada de un descenso en la expectativa de vida, mayor mortalidad infantil, aumento de enfermedades bucodentales (defectos del esmalte, caries, etc.) y prevalencia de afecciones infecciosas tales como la treponematosis (Rodríguez Cuenca, 2006).

Con el fin de aproximarse al estado de salud y a los procesos adaptativos de los individuos y las poblaciones a distintos econichos, la bioarqueología hace uso de algunas tendencias teóricas y metodológicas tales como los marcadores óseos de estrés/actividad (Rojas y Dotour, 2014; Rojas y Martín, 2014) y los análisis moleculares. Ejemplo del uso de estas metodologías es el trabajo de Gómez (2012), en el cual, desde una perspectiva a nivel regional, se muestran evidencias de marcadores óseos que relaciona con la transición en los patrones de subsistencia y alimentación, cambios a nivel demográfico y el aumento de relaciones intergrupales, resultado del desarrollo y dispersión de la horticultura durante el Holoceno medio. Los datos obtenidos llevan a la autora a inferir una alta capacidad adaptativa y de aprovechamiento de recursos de los cazadores-recolectores de la sabana de Bogotá, a la vez que reconoce múltiples respuestas a nivel óseo, manifestadas en el aumento de la frecuencia y severidad de algunos marcadores óseos que sirven como indicadores nutricionales (criba orbitaria, la hiperostosis porótica, hipoplasias del esmalte, caries, pérdida de dientes). No obstante, esto no debe entenderse necesariamente como una disminución en la calidad de vida de los individuos a través del tiempo.

En otra aproximación sobre esta misma línea metodológica y desde enfoques bioculturales, Valderrama (2012) reflexiona en su estudio acerca de la división sexual de las actividades físicas empleando la aproximación osteológica conocida como marcadores óseos de actividad (MOA). Uno de los puntos interesantes de este trabajo es la interpretación que hace de la relación entre las evidencias óseas (MOA), el sexo y la diversidad de recursos alimenticios y de materias primas reportadas para el área de estudio. De acuerdo con los resultados, las mujeres tienden a presentar con mayor frecuencia el marcador del tendón de Aquiles y del espolón plantar, por lo cual deduce 
que posiblemente transitaron por los variados paisajes para recolectar frutas, agua, leña y materias primas y posteriormente realizaron actividades en cuclillas o arrodilladas. En contraste, para el caso de los hombres, encuentra evidencias del desarrollo del músculo deltoides, asociado con actividades de carga y lanzamientos. A partir de estos hallazgos se colige la importancia de vincular este tipo de aproximaciones al conocimiento respecto a los patrones de movilidad (desde el punto de vista biomecánico) y diferentes actividades físicas (labores domésticas, por ejemplo) en los variados nichos del territorio nacional.

El moderno desarrollo de la biología molecular y la era genómica están desempeñando un papel cada vez más importante en la investigación arqueológica, proporcionando nuevas líneas de evidencia para una serie de cuestionamientos centrales de la bioarqueología, ya sea desde enfoques evolutivos del desarrollo de la enfermedad o desde enfoques bioculturales que vinculen, entre otros, organización social, adaptabilidad y medio ambiente y demás. Esto ha propiciado el surgimiento y desarrollo de la llamada bioarqueología molecular, definida como la disciplina encargada de analizar, a partir de métodos físico-químicos, la composición molecular de muestras antiguas de plantas, animales, seres humanos y agentes infectivos patógenos, haciendo especial énfasis en isótopos estables, residuos de lípidos, proteínas, oligoelementos y ADN antiguo (ADNa) (Rodríguez Saza, 2003).

La técnica de análisis de isótopos estables ofrece valiosa información sobre los patrones de dieta en las poblaciones prehispánicas y tiene una cierta tradición en el ámbito colombiano (Aristizábal, 2015; Cadena, 2010; Cárdenas, 1993; 1996; 2002; Castillo 1998; Delgado Burbano, 2018; Osorio, 2012; Van der Hammen, Correal y Van Klinken, 1990). En esta se estudian principalmente los isótopos estables $13 \mathrm{C} / 12 \mathrm{C}, 15 \mathrm{~N} / 14 \mathrm{~N}$ y 34S/32S para inferir el consumo de determinados grupos de plantas. En el caso del nitrógeno $(\mathrm{d} 15 \mathrm{~N})$, se obtienen evidencias el tipo de ingesta animal y de leguminosas, mientras que el azufre (d34S), presente en los suelos, se utiliza como indicador de procedencia y movilidad de los individuos en el pasado (Osorio, 2012).

Un amplio estudio a escala regional y temporal realizado por Cárdenas (2002) ofrece una amplia discusión acerca de la evidencia en el cambio de estrategias de subsistencia en la sabana de Bogotá, argumentando a partir del análisis de isótopos estables que los grupos de cazadores-recolectores del Holoceno medio y tardío basaron su subsistencia en la recolección de plantas silvestres por encima del consumo de carne derivada de la cacería. Este comportamiento fue transformándose hacia una dieta mixta en las sociedades agrícolas, en la cual prevalecieron la proteína tanto animal como vegetal y alimentos altamente procesados en forma de harinas y frutos silvestres.

Cabe destacar asimismo la investigación de Delgado Burbano et al. (2014), quienes ampliaron el panorama de la alimentación y subsistencia de los grupos muiscas durante el periodo tardío planteando interrogantes relacionados especialmente con la variación de la dieta según el estatus social. En este estudio los resultados indican gran diferencia entre los grupos de edad más que entre grupos sociales; por otra parte, las variaciones entre sexos demostraron que los individuos masculinos parecían tener un mayor consumo de maíz y productos derivados de este, hecho que sería congruente con los resultados encontrados para otras poblaciones muiscas, en las que el consumo de maíz y productos derivados (en forma de chicha) y una mayor ingesta de proteína se encuentran en el grupo masculino. 
Para la población de Tibanica, objeto del estudio de Delgado Burbano et al. (2014), la idea de una población desnutrida parece no tener asidero; más bien, los resultados de los análisis isotópicos muestran un grupo con una dieta relativamente homogénea. No obstante, parece ser que, aunque los individuos comían lo mismo, lo hacían en proporciones diferentes. Así, los individuos catalogados como de élite parecen haber tenido mayor acceso a carne de herbívoros, como los venados, que el resto de la población (Aristizábal, 2015). Adicionalmente, la incidencia de patologías como la hiperostosis porótica y la criba orbitaria parece no tener mayor diferencia entre la élite y la no élite; la hipoplasia del esmalte es la única variable que presenta variaciones significativas, que bien pueden estar relacionadas con una mejor protección durante los periodos de crisis (Langebaek et al., 2015).

En el estudio de sociedades jerarquizadas, como por ejemplo los muiscas, pensar el hecho alimentario más allá de la subsistencia y plantear el uso de las unidades domésticas/áreas de actividad como correlatos básicos para entender el fenómeno alimentario (Jaramillo, 2012) conlleva, en términos teórico-metodológicos, un avance importante que tendrá en el contexto colombiano grandes implicaciones, especialmente en los estudios bioarqueológicos y moleculares, relacionados con la apropiación de recursos, salud, dieta y nutrición. En este sentido, Galindo et al. (2013), usando muestras de material cerámico del periodo temprano y tardío de la población muisca de Sutamarchán (Boyacá), efectuaron la extracción química de ácidos grasos contenidos en el interior de la matriz arcillosa $\mathrm{y}$, posteriormente, los identificaron a través de cromatografía de gases/espectrometría de masa. De este modo pudieron plantear inferencias respecto a los posibles alimentos que fueron seleccionados por la población prehispánica como parte de su dieta en cada uno de estos periodos.

Para el estudio de sociedades agroalfareras, la estrategia de análisis de fragmentos cerámicos o vasijas completas (desde el punto de vista clásico de la forma y función), recuperados de unidades domésticas, ha permitido aproximarse a la distinción de los tipos de cerámica que eran usualmente usados por las poblaciones prehispánicas en el procesamiento, la cocción o el almacenamiento de un determinado alimento o sus derivados. No obstante, la incorporación en este tipo de estudios arqueológicos de análisis isotópicos del carbono de los lípidos $(\delta 13 \mathrm{C})^{13}$, presente en huesos humanos y animales (Colonese et al., 2015; Evershed, Turner, Hedges, Tuross y Leyden, 1995; Makarewikcz y Sealy, 2015), así como de un riguroso estudio tafonómico, resultaría una aproximación útil que permitiría identificar la presencia de ácidos grasos esenciales de la dieta directamente del hueso y compararlos con los resultados del perfil de ácidos grasos del material cerámico.

Desde el punto de vista de las aplicaciones moleculares, otra aproximación importante de los biomarcadores lipídicos ha sido la diagnosis de la tuberculosis y la lepra en casos arqueológicos. Aunque el análisis genético proporciona las pruebas necesarias para la detección de la presencia de Mycobacterium tuberculosis, microorganismo causante de la tuberculosis, en especímenes muy degradados, la preservación bioquímica del ADN no es la óptima. El M. tuberculosis se caracteriza por la presencia inusual de lípidos en la membrana celular, lo que le confiere un alto potencial como biomarcador específico. Así, el uso de marcadores moleculares en la discusión de la prevalencia de determinados

${ }^{13} \mathrm{El}$ análisis de isótopos estables de los lípidos presentes en el hueso ha recibido mucha menos atención a nivel arqueológico, en parte debido a la falta de metodologías adecuadas que permitan la recuperación suficiente de compuestos para la caracterización estructural e isotópica. 
agentes infecciosos tales como la treponematosis (agente de la sífilis y/o yaws) y la tuberculosis se ha hecho en varios sentidos: verificar la presencia de un determinado agente infectivo a nivel individual y/o poblacional, validar el diagnóstico paleopatológico hecho a nivel macroscópico ${ }^{14}$, y aportar en la discusión epidemiológica sobre la evolución y distribución del patógeno alrededor del mundo y a lo largo del tiempo.

La transición epidemiológica entre grupos con diferentes estrategias de subsistencia ha sido un tema de amplio debate en la bioarqueología colombiana (Rodríguez Cuenca, 2006; 2011). En este sentido, se ha aducido mayor presencia de infecciones treponematósicas (sífilis) en cazadores-recolectores, en contraste con la mayor incidencia de tuberculosis para poblaciones sedentarias y agrícolas. Hoy en día, además, la bioarqueología molecular ha aportado datos interesantes acerca de la coevolución de los agentes patógenos a través de la secuenciación de amplias secciones del genoma de diferentes microorganismos y de su análisis filogenético y filogeográfico, para evaluar la virulencia —así como la prevalencia— de la enfermedad en el tiempo.

Los estudios moleculares -y particularmente en $\mathrm{ADN}$ antiguo ${ }^{15}$ - en Colombia han avanzado notablemente en los últimos años (Alape, 1998; Barreto et al., 2007; Casas et al., 2011; Díaz, 2015; Fernández, 1999; Guhl y Cárdenas, 1995; Langebaek, Gómez, Groot, Pérez y Rodríguez, 2012; Monsalve, 1996; Pérez, 2016; Puerto, Cortina y Rey 2010; Rincón, 2000; Rodríguez Saza, 2003; Silva et al., 2008, entre otros), centrándose en el análisis de restos humanos óseos y momificados con el fin de ahondar en la discusión sobre poblamiento, dispersión y relaciones de parentesco desde enfoques ecológicos, evolutivos y bioculturales. Dichos avances han dejado entrever una amplia diversidad genética aún desde periodos muy tempranos y han sido esenciales en la identificación de patógenos.

Para poner un ejemplo, uno de los trabajos pioneros en Colombia en la materia corresponde al de Burgos, Correal y Arregoces (1994), quienes a través de técnicas inmunológicas de anticuerpos fluorescentes antitreponema con suero absorbido (FTAABS) confirmaron la presencia de treponematosis en restos óseos colectados del sitio Aguazuque, con una antigüedad de 5.000 años antes del presente (precerámico). Este análisis se convirtió en la primera demostración de infección por Treponema pallidum efectuada en restos óseos tan antiguos en Colombia. Por su parte, Sotomayor, Burgos y Arango (2004) describen los resultados positivos en el estudio de genes de la fracción $16 \mathrm{~S}$ del ribosoma en una momia de filiación cultural guane que mostraba una clara evidencia de tuberculosis vertebral responsable de la presencia de una cifosis angular o mal de Pott, lesión característica en los individuos con tuberculosis vertebral.

Hasta la fecha, nuevas preguntas se abren paso en el país en materia investigativa, lo que abre un panorama de inflexión para el conocimiento de las poblaciones del pasado. Las técnicas moleculares, entre otras técnicas y metodologías multidisciplinarias, ofrecen nuevas rutas para las inferencias sobre la subsistencia, la dieta y el binomio saludenfermedad de los pobladores que habitaron el territorio nacional.

\footnotetext{
${ }^{14}$ Especialmente en aquellos casos en los cuales una manifestación a nivel óseo podría tener múltiples causas o el individuo pudo haber fallecido a causa de una infección cuya fase de desarrollo no deja manifestaciones clínicas macroscópicamente visibles en el tejido óseo.

${ }^{15}$ ADN antiguo: el $a D N A$ refiere a algún segmento o traza de ADN de un organismo muerto o parte de él, así como a segmentos de ADN de un organismo vivo encontrado de manera extracorporal (Guhl y Aufderhide, 2007).
} 


\section{Conclusiones}

Los materiales óseos, los dientes y los individuos momificados constituyen bibliotecas morfológicas y moleculares a través de las cuales se puede llegar a un acercamiento cada vez más profundo de la calidad de vida de las poblaciones en el pasado desde enfoques evolutivos, ecológicos y bioculturales. Desde la década de los sesenta se ha avanzado ampliamente en este aspecto dentro de la arqueología colombiana; sin embargo, sigue siendo una tarea pendiente examinar críticamente los presupuestos teóricos y las inferencias alcanzadas hasta el momento en cuanto a la calidad y profundidad de la información bioarqueológica obtenida y usada como parte de los esquemas de desarrollo sociocultural que conocemos en la actualidad respecto a la relación entre las estrategias de subsistencia, la dieta y el estado de salud-enfermedad de las poblaciones prehispánicas.

Estos presupuestos teóricos han quedado supeditados por el asombro de la sofisticación de las nuevas técnicas que se aplican a la diversidad de la materialidad. En este sentido, las perspectivas teóricas - tendientes a problematizar la dicotomía continuidaddiscontinuidad de las poblaciones, rutas migratorias, adaptación al medio, cambios culturales y condiciones de vida, y relaciones bioculturales entre organización social y estados de salud-enfermedad- y los nuevos métodos de investigación han entrado en una disputa para la solución de los viejos paradigmas. Los resultados de esta discusión han permitido en algunos casos y en ciertas regiones del país reinterpretar nuevas preguntas que han permitido, en el nuevo siglo, una mayor integración y aplicación de líneas investigativas.

Sin ser una revisión exhaustiva, los ejemplos descritos a lo largo del texto, a escalas macrorregional, regional, local e individual, son prueba de que los arqueólogos colombianos están interesados cada día más en la formulación de preguntas más refinadas sobre el contexto biocultural, evolutivo y ecológico. Nuevos datos sobre la alteración de los ecosistemas por parte de los pobladores tempranos del territorio colombiano; la alta divergencia morfológica en los grupos de cazadores recolectores, seguida de una relativa homogeneidad morfológica de los grupos agricultores; múltiples evidencias a nivel óseo (huellas de actividades físicas y procesos nutricionales producto de los cambios en las estrategias de subsistencia y en la incorporación de una nueva dieta); la identificación bioquímica del tipo de alimentos consumidos; la relación entre el fenómeno alimentario, las unidades de vivienda y los correlatos bioarqueológicos y, finalmente, el uso de marcadores moleculares tanto para estudios poblacionales como para la identificación de determinados agentes infectivos patógenos constituyen solo algunas de las tendencias investigativas en desarrollo por los arqueólogos en el contexto colombiano.

\section{Referencias}

Aceituno, F. (2001a). Identificación de plantas alimenticias en el Cauca medio durante el Holoceno temprano y medio. Boletín de Antropología, 15, 51-72.

Aceituno, F. (2001b). De la arqueología temprana de los bosques premontanos de la Cordillera Central colombiana. En S. Botero (Ed.), Construyendo el pasado: Cincuenta años de arqueología en Antioquia (pp. 157-183). Medellín, Colombia: Universidad de Antioquia.

Aceituno, F. (2002). Interacciones fitoculturales en el Cauca medio. Revista del Área Intermedia, 4, 89-113.

Aceituno, F. y Lalinde, V. (2011). Residuos de almidones y el uso de plantas durante el Holoceno Medio en el Cauca Medio (Colombia). Caldasia, 33(1), 1-20. 
Aceituno, F. y Loaiza, N. (2014). Early and Middle Holocene Evidence for Plant Use and Cultivation in the Middle Cauca River Basin, Cordillera Central (Colombia). Quaternary International Reviews, 86, 49-62.

Aceituno, F., Loaiza, N., Delgado-Burbano, M. y Barrientos, G. (2013). The Initial Human Settlement of Northwest South America During the Pleistocene/Holocene Transition: Synthesis and Perspectives. Quaternary International, 301, 23-33.

Alape, J. (1998). Caracterización genética de restos antiguos de poblaciones indígenas de Colombia, mediante diez loci con repeticiones cortas en tándem (STR's) (Tesis de grado). Departamento de Biología. Universidad Nacional de Colombia.

Andrade, A. (1986). Investigaciones arqueológicas en los antrosoles de Ararracuara. Bogotá, Colombia: Fundación de Investigaciones Arqueológicas Nacionales. Banco de la República

Archila, S. (1993). Medio ambiente y arqueología de las tierras bajas del Caribe Colombiano. Boletín del Museo del Oro, 34-35, 111-164.

Ardila, G. (1984). Chía. Un sitio precerámico en la sabana de Bogotá. Bogotá, Colombia: Fundación de Investigaciones Arqueológicas Nacionales. Banco de la República.

Aristizábal, L. (2015). Alimentación y sociedad. Paleodieta de una población muisca de la sabana de Bogotá, El caso de Tibanica -Soacha (Tesis doctoral). Universidad de los Andes.

Armelagos, G. y Barnes, K. (1999). The Evolution of Human Disease and the Rise of Allergy: Epidemiological Transitions. Medical Anthropology, 18, 187-213.

Armelagos, G., Brown, P. y Turner, B. (2005). Evolutionary, Historical and Political Economic Perspectives on Health and Disease. Social Science and Medicine, 61, 755-765.

Barnes, K., Armelagos, G. y Morreale, S. (1999). Darwinian Medicine and the Emergency of Allergy. En W. Trevathan (Ed.), Evolutionary Medicine (pp. 209243). Nueva York, Estados Unidos: Oxford University Press.

Barreto, G., Rodríguez, C., Braga, Y., Quintero, M., Hurtado, L., Arias, L. y Rodríguez, E. (2007). Extracción y amplificación de ADN arqueológico de dos poblaciones prehispánicas del suroccidente colombiano. International Journal of South American Archaeology, 6, 48-59.

Boada, A. M. (1988). Las patologías óseas en la población de Marín. Boletín de Arqueología, 3(1), 3-24.

Bocquet Appel, J. P. y Bar-Yosef, O. (2008). The Neolithic Demographic Transition and its Consecuences. Nueva York, Estados Unidos: Springer.

Bongaarts, J. (2009). Human Population Growth and the Demographic Transition. Philosophical Transactions of the Royal Society, 364, 2985-2990.

Burgos, J., Correal, G. y Arregoces, C. (1994). Treponematosis en restos óseos precerámicos de Colombia. Revista de la Academia Colombiana de Ciencias Exactas, Físicas y Naturales, 19(73), 237-241.

Burton, J. y Wright, L. (1995). Non-Linearity in the Relationship Between Bone Sr/Ca and Diet: Paleodietary Implications. American Journal of Physical Anthropology, 96, 273-282.

Buzon, M. (2012). The Bioarchaeological Approach to Paleopathology. En A. Grauer (Ed.), A Companion to Paleopathology (pp. 58-75). Oxford, Reino Unido: Blackwell Publishing Ltd.

Cadena, B. (2010). Isótopos estables, subsistencia en interpretación arqueológica en el caso e Tubará (Tesis de maestría). Departamento de Antropología, Universidad de los Andes. 
Cárdenas, F. (1990). Mitos y verdades sobre la desnutrición entre los muiscas: Una visión crítica. Revista de Antropología y Arqueología, 4(1), 129-139.

Cárdenas, F. (1993). Paleodieta y paleodemografía en poblaciones arqueológicas muiscas. Revista Colombiana de Antropología, 30, 131-148.

Cárdenas, F. (1995). La dieta prehispánica entre los muiscas. Una autoevaluación crítica. Revista Colombiana de Antropología, 32, 305-309.

Cárdenas, F. 1996. La dieta prehispánica en poblaciones arqueológicas muiscas. En: Therrien, M y Enciso, B.(Eds.). Bionatropología de la sabana de Bogotá. Bogotá: Instituto colombiano de antropología, p. 85-109

Cárdenas, F. (1998). Mummies from Colombia and other South American Areas. An Archaeological Context. En E. Cockburn y T. Reyman (Eds.), Mummies, Disease and Ancient Cultures (pp. 197-219). Cambridge, Reino Unido: Cambridge University Press.

Cárdenas, F. (2002). Datos sobre la alimentación prehispánica en la sabana de Bogotá. Bogotá, Colombia: Instituto Colombiano de Antropología e Historia.

Casas, A., Gómez, A., Briceño, I., Díaz, M., Bernal, J. y Rodríguez, J. V. (2011). High Genetic Diversity on a Sample of Precolumbian Bone Remains from Guane Territories in Northwestern Colombia. American Journal of Physical Anthropology, 146, 637-649.

Castillo, N. (1998). Los antiguos pobladores del valle medio del río Porce. Aproximación inicial desde el estudio arqueológico del proyecto Porce II. Medellín, Colombia: Empresas Públicas de Medellín-Universidad de Antioquia.

Castillo, N. y Aceituno, J. (2000). Un modelo de ocupación durante el Holoceno Temprano y Medio en el noroccidente colombiano: el valle medio del río Porce. Arqueoweb: Revista sobre Arqueología en Internet, 2(2), 4-26.

Castillo, N. y Aceituno, J. (2006). El bosque domesticado, el bosque cultivado: Un proceso milenario en el valle medio del río Porce en el noroccidente colombiano. Latin American Antiquity, 17(4), 561-578.

Cavelier, I., Mora, S. y Herrera, L. (1990). Estabilidad y dinámica agrícola. En S. Mora (Ed.), Ingenierías prehispánicas (pp. 73-11). Bogotá, Colombia: FEN-Instituto Colombiano de Antropología.

Cavelier, I., Rodríguez, C., Herrera, L., Morcote, G. y Mora, S. (1995). No solo de caza vive el hombre: ocupación del bosque amazónico, Holoceno Temprano. En I. Cavelier y S. Mora (Eds.), Ámbito y ocupaciones tempranas de la América Tropical (pp. 27-44). Bogotá, Colombia: Erigaie-Instituto Colombiano de Antropología.

Civera, M. (2005). Avances y retos en la determinación de la salud de poblaciones antiguas a partir de restos esqueléticos. Estudios de Antropología Biológica, XII, 859-870.

Cohen, M. y Crane-Kramer, G. (2003). Ancient Health. Skeletal Indicators of Agricultural and Economic Intensification. Gainisville, Florida, Estados Unidos: University Press of Florida.

Colonese, A., Farrell, T., Lucquin, A., Firth, D., Charlton, S., Robson, H., Alexander, M y Craig, O. (2015). Arcaheological Bone Lipids as Palaeodietary Markers. Rapid Communications in Mass Spectrometry, 29, 611-618.

Corcione, M. A. (2016). Condiciones de vida y diferenciación social entre los muiscas: Análisis bioarqueológico de los fenómenos porosos en el cráneo. El caso de Tibanica, Soacha (Tesis doctoral). Universidad de los Andes. 
Correal, G. (1979). Investigaciones arqueológicas en abrigos rocosos de Nemocón y Sueva. Bogotá, Colombia: Fundación de Investigaciones Arqueológicas Nacionales. Banco de la República.

Correal, G. (1981a). Evidencias culturales y megafauna pleistocénica en Colombia. Bogotá, Colombia: Fundación de Investigaciones Arqueológicas Nacionales. Banco de la República.

Correal, G. (1981b). Evidencias culturales asociadas a megafauna durante el Pleistoceno Tardío de Colombia. Revista CIAF, 6(1-3), 119-176.

Correal, G. (1990). Aguazuque. Evidencias de cazadores, recolectores y plantadores en la altiplanicie de la Cordillera Oriental. Bogotá, Colombia: Fundación de Investigaciones Arqueológicas Nacionales. Banco de la República.

Correal, G. (1996). Apuntes sobre la paleopatología precolombina. En B. Enciso y M. Therrien (Eds.), Bioantropología de la sabana de Bogotá, siglos VIII al XVI d. C. (pp. 145-161). Bogotá, Colombia: Instituto Colombiano de Antropología.

Correal, G. y Pinto, M. (1983). Investigación arqueológica en el municipio de Zipacón, Cundinamarca. Bogotá, Colombia: Fundación de Investigaciones Arqueológicas Nacionales. Banco de la República.

Correal, G. y Van der Hammen, T. (1977). Investigaciones arqueológicas en los abrigos rocosos del Tequendama. Bogotá, Colombia: Biblioteca Banco Popular.

Delgado Burbano, M. (2007). El impacto de la colonización española: evidencias paleopatológicas e isotópicas de cambios en la salud oral y reducción de la diversidad en la dieta en sociedades coloniales nativas del suroccidente de Colombia. Estomatología, 15(2), 17-37.

Delgado Burbano, M. (2012a). Mid and Late Holocene Population Changes at the Sabana de Bogotá (Northern South America) Inferred from Skeletal Morphology and Radiocarbon Chronology. Quaternary International, 256, 2-11.

Delgado Burbano, M. (2012b). Diversificación morfológica y poblamiento temprano del noroccidente de Suramérica: un estudio de la variación craneofacial. Revista Colombiana de Antropología, 48(1), 189-232.

Delgado Burbano, M. (2017). Sinopsis de la arqueología y la bioantropología del poblamiento temprano del noroccidente de Suramérica. Revista Colombiana de Antropología, 53(1), 213-239.

Delgado Burbano, M. (2018). Stable Isotope Evidence for Dietary and Cultural Change Over the Holocene at the Sabana de Bogotá Region, Northern South America. Archaeological and Anthropological Science, 10(4), 817-832.

Delgado, M. y Rosique, J. (2012). Introducción. Revista Colombiana de Antropología, 48(1), 11-19.

Delgado, M., Langebaek, C., Aristizábal, L., Tykot, R. y Johnson, L. (2014). Indicadores bioquímicos de dieta en Tibanica, un poblado muisca tardío en la sabana de Bogotá (Colombia): Isótopos estables $(\delta 13 \mathrm{Ccol}, \delta 13 \mathrm{Cap}$ y $\delta 15 \mathrm{~N})$ y elementos traza (Ba y Sr). En L. Luna, C. Aranda y J. Suby (Eds.), Avances recientes de la bioarqueología latinoamericana (pp. 103-128). Buenos Aires, Argentina: Grupo de Investigación en Bioarqueología (GIB).

DeWhite, S. y Stojanowski, C. (2015). The Osteological Paradox 20 Years Later: Past Perspectives, Future Directions. Journal of Archaeological Research, 23(4), pp. $1-54$.

Díaz, M. (2015). Caracterización genética de un grupo Paleoamericano Checua proveniente de Nemocón - Cundinamarca, Colombia: Implicaciones para el Poblamiento Temprano de Suramérica (Tesis doctoral). Universidad Javeriana. 
Eden, M., Bray, W., Herrera, L. y McEwan, C. (1984). Terra Preta Soils and Their Archaeological Context in the Caquetá Basin of Southeast Colombia. American Antiquity, 49(1), 125-140.

Enciso, B. (1993). El ocaso del sol de los venados. Arqueología de rescate en la Sabana de Bogotá. Revista Colombiana de Antropología, 30, 149-182.

Enciso, B. (1996). Fauna asociada a tres asentamientos muiscas del sur de la sabana de Bogotá, siglos VIII-XIV D.C. En M. Therrien y B. Enciso (Eds.), Bioantropología de la sabana de Bogotá (pp. 41-58). Bogotá, Colombia: Instituto Colombiano de Antropología.

Evershed, R., Turner, G., Hedges, R., Tuross, N. y Leyden, A. (1995). Preliminary Results for the Analysis of Lipids in Ancient Bone. Journal of Archaeological Science, 22(2), 277-290.

Fernández, J. C. (1999). Arqueología molecular aplicada a la solución de problemas prehistóricos: Análisis de ADN mitocondrial en momias y restos óseos prehispánicos (Tesis para optar al título de antropólogo). Departamento de Antropología, Universidad Nacional, Bogotá.

Galindo, R., Castro, B. y Henderson, H. (2013). Extracción e identificación de los ácidos grasos contenidos en el interior de la cerámica muisca, a través de cromatografía de Gases/espectrometría de masas, para la población prehispánica de Sutamarchán (Colombia), en los periodos temprano y tardío. En $4^{o}$ Simposio Latinoamericano de Métodos de Física y Química en Arqueología, Arte y conservación de patrimonio cultural. LASMAC, 16, 17 y 18 de octubre.

Gil, B. (2011). Fitolitos en cálculo dental de poblaciones Tempranas del valle geográfico del río Cauca (500 a. C.-500 d. C.). Aproximación a la paleodieta (Tesis de maestría). Universidad Nacional de Colombia.

Gnecco, C. (1994). Tecnología de cazadores-recolectores subandinos: análisis funcional y organización tecnológica. Revista Colombiana de Antropología, 31, 5-31.

Gnecco, C. (1997). Cazando mastodontes, recolectando palmas: un ejercicio revisionista de las investigaciones arqueológicas sobre cazadores recolectores en Colombia, o de la cronología en arqueología y otros asuntos. En S. Mora y F. Flórez (Eds.), Nuevas memorias sobre las antigüedades neogranadinas (pp.2944). Bogotá, Colombia: Fundación de Investigaciones Arqueológicas Nacionales.

Gnecco, C. (2000). Ocupación temprana de bosques tropicales de montaña. Popayán, Colombia: Editorial Universidad del Cauca.

Gnecco, C. y Aceituno, J. (2004). Poblamiento temprano y espacios antropogénicos en el norte de Suramérica. Complutum, 15, 151-164.

Gnecco, C. y Mora, S. (1997). Late Pleistocene/Early Holocene Tropical Forest Occupations at San Isidro and Peña Roja, Colombia. Antiquity, 71(273), 683-690.

Gnecco, C. y Salgado, H. (1989). Adaptaciones precerámicas en el suroccidente de Colombia. Boletín Museo del Oro, 24, 35-53.

Gómez, J. (2011). Salud y cambio social: la bioarqueología y su potencial para interpretar el impacto biológico de la agricultura. Boletín de Antropología, 26(43), 192-214.

Gómez, J. (2012). Análisis de marcadores óseos de estrés en poblaciones del Holoceno Medio y Tardío inicial en la Sabana de Bogotá, Colombia. Revista Colombiana de Antropología, 48(1), 143-168.

Goodman, A. (1998). Skeletal Growth and Time of Agricultural Intensification. En S. Ulijaszek, F. Johnston y M. Preece (Eds.), The Cambridge Encyclopedia of Human Growth and Development (pp.387-389). Cambridge, Reino Unido: Cambridge University Press. 
Goodman, A. y Leatherman, T. (1998). Traversing the Chasm Between Biology and Culture: An Introduction. En A. Goodman y T. Leatherman (Eds.), Building a new biocultural synthesis: Political-economic perspectives on human biology (pp. 341). Michigan, Estados Unidos: The University of Michigan Press.

Goodman, A., Swedlund, A., Brooke, T. y Armelagos, G. (1988). Biocultural Perspectives on Stress in Prehistoric. Historical and Contemporary Population Research. Yearbook of Physical Anthropology, 31, 169-202.

Goody, J. (1995). Cocina, cuisine y clase: estudio de sociología comparada. Barcelona, España: Editorial Gedisa.

Grigg, D. (1995). The Nutritional Transition in Western Europe. Journal of Historical Geography, 22(1), 247-261.

Guhl, F. y Auderheide, A. (2007). Archaeological Epidemiology of Infectious Diseases: Fossil DNA. En T. Tibayrenc (Ed.), Encyclopedia of Infectious Diseases. Modern Methodologies (pp. 459-473). Hoboken, Nueva Jersey, Estados Unidos: Wiley \& Sons.

Guhl, F. y Cárdenas, F. (1995). Paleoparasitología, paleopatología y genéticaprehistórica: un estudio interdisciplinario en momias arqueológicas. Bogotá, Colombia: Fundación para la Promoción de la Investigación y la Tecnología. Banco de la República.

Herrera, L. (1981). Relaciones entre ocupaciones prehispánicas y suelos negros en la cuenca del río Caquetá en Colombia. Revista CIAF, 6(1-3), 225-242.

Herrera, L. (1985). Agricultura aborigen y cambios de vegetación en la Sierra Nevada de Santa Marta. Bogotá, Colombia: Fundación de Investigaciones Arqueológicas Nacionales, Banco de la República.

Huss-Ashmore, R., Goodman, A. y Armelagos, G. (1982). Nutritional Inference from Paleopathology. En M. Schiffer (Ed.), Advances in Archaeological Method and Theory (pp. 395-474). Nueva York, Estados Unidos: Academic Press.

Jaramillo, L. G. (2012). Entre "Grandes Esquemas" y "Escalas Pequeñas": Reflexiones metodológicas sobre los estudios alimentarios y de vida doméstica en el altiplano Cundiboyacense (Colombia). En M. P. Babot, M. Marschoff y F. Pazzarelli (Eds.), Las manos en la masa. Arqueologías, Antropologías e Historias de la Alimentación en Suramérica (pp. 93-118). Córdoba, Argentina: Museo de Antropología (UNC) e ISES (CONICET-UNT).

Klaus, H. (2014). Frontiers in the Bioarchaeology of Stress and Disease: CrossDisciplinary Perspectives from Pathophysiology, Human Biology, and Epidemiology. American Journal of Physical Anthropology, 155(2), 294-308.

Lanata, J. L., Martino, L., Osellac, A. y Garcia-Herbstd, A. (2008). Demographic Conditions Necessary to Colonize New Spaces: The Case for Early Human Dispersal in the Americas. World Archaeology, 40(4), 520-537.

Langebaek, C. (1990). Patologías en la población muisca y la hipótesis de la economía autosuficiente. Revista de Antropología y Arqueología, 6(1), 143-157.

Langebaek, C. (1994). Dieta y desarrollos prehispánicos en Colombia. Credencial Historia, 60, 4-7.

Langebaek, C. (2011). Preguntas sin respuestas y cuestiones sin preguntas: Algunas notas sobre los procesos de ocupación humana en la Colombia prehispánica. En V. González (Comp.), Arqueología en el área intermedia (pp. 223-282). Bogotá, Colombia: Instituto Colombiano de Antropología e Historia.

Langebaek, C., Bernal, M., Aristizábal, L., Corcione, M. A., Rojas, C. y Santa, T. (2011). Condiciones de vida y jerarquías sociales en el norte de Suramérica: el caso de la población muisca Tibanica Soacha. Indiana, 28, 15-34. 
Langebaek, C., Gómez, A., Groot, H., Pérez, L. A. y Rodríguez, F. (2012). Parentesco y Status. En C. Langebaek (Comp.), Vivir y Morir en Tibanica-reflexiones sobre el poder político en una comunidad muisca de la Sabana de Bogotá (pp. 104-115). Bogotá, Colombia: Universidad de los Andes.

Langebaek, C., Jaramillo, A., Aristizábal, L., Bernal, M., Corcione, M. A., Mendoza, L., Pérez, L., Rodríguez, F. y Zorro, C. (2015). Vivir y morir en Tibanica: reflexiones sobre el poder y el espacio en una aldea muisca tardía de la sabana de Bogotá. Revista Colombiana de Antropología, 52(2), 173-207.

Langsjoen, O. (1998). Diseases of the Dentition. En A. Aufderheide y C. RodríguezMartin (Eds.), The Cambridge Encyclopedia of Human Paleopathology. Cambridge, Reino Unido: Cambridge University Press.

Larsen, C. (2001a). Alimentación y salud de los indígenas en las colonias americanas. Investigación y Ciencia, 287, 42-47.

Larsen, C. (2001b). Bioarchaeology of Spanish Florida: The Impact of colonialism. Gainesville, Estados Unidos: Florida Museum of Natural History.

Larsen, C. (2015). Bioarchaeology: Interpreting Behavior from Human Skeleton. Cambridge, Inglaterra: Cambridge University Press.

Lieben, R. (1973). Medical Anthropology. En J. Honigmann y A. Alland (Eds.), Handbook of Social and Cultural Anthropology. Chicago: Rand McNally Co.

López, C. (1989). Evidencias paleoindias en el valle medio del río Magdalena (municipios de Puerto Berrío, Yondó y remedios, Antioquia). Boletín de Arqueología, 4(2), 3-23.

López, C. (1994). Aproximaciones al medio ambiente, recursos y ocupación temprana del valle medio del río Magdalena. Informes Antropológicos, 7, 5-15.

López, C. (1999). Ocupaciones tempranas en las tierras bajas tropicales el valle medio del río Magdalena, sitio 05-YON-002, Yondó-Antioquia. Bogotá, Colombia: Fundación de Investigaciones Arqueológicas Nacionales, Banco de la República.

Luna, L. (2006). Alcances y limitaciones del concepto de estrés en bioarqueología. Antípoda, 3, 255-279.

Makarewikcz, C. y Sealy, J. (2015). Dietary Reconstruction, Mobility, and the Analysis of Ancient Skeletal Tissues: Expanding the Prospects of Stable Isotope Research in Archaeology. Journal Archaeological Science, 56, 146-158.

McKee, J. (2010). Taphonomic Processes of Bone Distribution and Deposition in the Tufa Caves of Taung, South Africa. Journal of Taphonomy, 8(2-3), 203-213.

Messer, E. (1995). Un estado de la cuestión. Perspectivas antropológicas sobre la dieta. Alimentación y cultura: necesidades, gustos y costumbres. Barcelona: Universitat de Barcelona.

Monsalve, M. V. (1996). ADN Antiguo: su impacto en la investigación científica. Innovación y Ciencia, 5(5), 46-51.

Mora, S. y Gnecco, C. (2002). Archaeological Hunter-Gatherers in Tropical Forests: a View from Colombia. En J. Mercader (Ed.), Under the Canopy: Archaeological Studies on the Hunter-Gatherer Colonization of the Tropical Forest Belt (pp.217290). New Brunswick, Canadá: Rutgers University Press.

Mora, S., Herrera, L., Cavelier, I. y Rodríguez, C. (1991). Cultivars, Anthropic Soils and Stability. A Preliminary Report of Archaeological research in Araracuara, Colombian Amazonia. Pittsburgh, Estados Unidos: University of Pittsburgh.

Morcote, G. (2008). Antiguos habitantes en ríos de aguas negras. Ecosistemas de cultivos en el interfluvio Amazonas-Putumayo. Colombia-Brasil. Bogotá, Colombia: ICN-Universidad Nacional de Colombia. 
Morcote, G. y Cavelier, I. (1999). Estrategias adaptativas y subsistencias en grupos humanos precolombinos del Medio Magdalena, Colombia. Revista de la Academia Nacional de Ciencias Exactas, Físicas y Naturales, 23, 1-48.

Neves, W. (1984). Estilo de vida e osteobiografía: a reconstituiçao do comportamento pelos ossos humanos. Revista de Pré-Historia, 6, 287-291.

Osorio, K. (2012). Aportes al estudio paleodietario mediante el análisis de isótopos estables de d13C y d15N en restos óseos humanos de la región centro-oriental del Cauca medio. Revista Colombiana de Antropología, 48(1), 125-141.

Oyuela-Caicedo, A. (1996). The Study of Collector Variability in the Transition to Sedentary Food Producers in Northern Colombia. Journal of World Prehistory, 10(1), 49-93.

Parra, R. (2001). Identificación de fitolitos en el cálculo dental de individuos prehispánicos de Tunja (Boyacá) y Soacha (Cundinamarca). En J. V. Rodríguez (Ed.), Los chibchas: Adaptación y diversidad en los Andes Orientales de Colombia (pp. 237-250). Bogotá, Colombia: Universidad Nacional de Colombia.

Peña, G. (2013). Pescadores de los raudales del río Magdalena durante el periodo Formativo Tardio (Siglos V al I a. C.). Bogotá, Colombia: Universidad Nacional de Colombia.

Pérez, L. A. (2016). Aportes genéticos para el entendimiento de la organización social de la comunidad muisca Tibanica (Soacha, Cundinamarca) (Tesis doctoral). Universidad de los Andes, Bogotá.

Pérez Lezaun, A. y Bertranpetit, J. (2000). La diversidad del genoma humano: de la enfermedad a la historia genética. En S. Grisolia (Ed.), Compromisos con el futuro del proyecto genoma humano (pp. 43-54). España: Fundación BBV.

Perosino, M. C. (2005). Los antropólogos biólogos y los profesionales de la salud frente al concepto de raza (Tesis de licenciatura en Ciencias Antropológicas). Universidad de Buenos Aires.

Posada, W. (2014). Una revisión crítica de la sistemática y las metodologías desde una perspectiva arqueológica. Boletín de Antropología, 29(48), 164-186.

Puerto, Y., Cortina, G. y Rey, M. (2010). Evaluación preliminar de tres métodos de aislamiento de ADN a partir de restos óseos muiscas hallados en predios de la Universidad Pedagógica y Tecnológica de Colombia sede Tunja. Bogotá, Colombia: Unidad de Paternidad. Instituto de Genética, Universidad Nacional de Colombia.

Ramos, E. (2002). Patrones de consumo de fauna como indicadores de cambio sociocultural: el caso de la Quinta de Bolívar. Revista de Antropología y Arqueología, 13(1), 147-168.

Ramos, E. y Archila, S. (2008). Arqueología y subsistencia en Tubará. Siglos IX-XVI. Bogotá, Colombia: Ceso Uniandes.

Renfrew, C. y Bahn, P. (2011). Archaeology: Theories, Methods and Practice. Londres, Inglaterra: Thames and Hudson.

Rincón, M. (2000). Comparación de tres métodos de extracción para amplificar ADN mitocondrial en restos óseos humanos antiguos (Tesis de grado). Departamento de Biología, Universidad INCCA.

Rodero, E. y Herrera, M. (2000). El concepto de raza. Un enfoque epistemológico. Arch. Zootec., 49, 5-16.

Rodríguez, C. (2005). La antropología dental y su importancia en el estudio de los grupos humanos. Revista Facultad de Odontología Universidad de Antioquia, 16(1-2), 52-59. 
Rodríguez, C. (2009). Asimetría del desgaste oclusal bilateral en dentición permanente y su relación con la paleodieta en una sociedad prehispánica de tradición cultural sonso en Colombia. Revista Facultad de Odontología Universidad de Antioquia, 1(28), 65-74.

Rodríguez, C. (2013). Revisión del rasgo premolar Uto-Azteca en Sudamérica y su presencia en Colombia. Revista de la Facultad de Odontología Universidad de Antioquia, 25(1), 147-157.

Rodríguez Cuenca, J. V. (1987). Análisis osteométrico, osteoscópico, patológico y dental de los restos de Soacha. Bogotá, Colombia: Instituto Colombiano de Antropología.

Rodríguez Cuenca, J. V. (1999). Los chibchas: pobladores antiguos de los andes orientales. Adaptaciones bioculturales. Bogotá, Colombia: FIAN.

Rodríguez Cuenca, J. V. (2001). Los chibchas. Adaptación y diversidad en los Andes orientales de Colombia. Bogotá, Colombia: Universidad Nacional de Colombia, Colciencias.

Rodríguez Cuenca, J. V. (2006). Las enfermedades en las condiciones de vida prehispánica de Colombia. Bogotá, Colombia: Universidad Nacional de Colombia.

Rodríguez Cuenca, J. V. (2007). La diversidad poblacional de Colombia en el tiempo y en el espacio: estudio craneométrico. Revista de la Academia Colombiana de Ciencias, 31(120), 321-346.

Rodríguez Cuenca, J. V. (2011). Los chibchas: Hijos del sol, la luna y los Andes: Orígenes de su diversidad. Bogotá, Colombia: Instituto de Desarrollo Urbano (IDU)-Universidad Nacional de Colombia.

Rodríguez Cuenca, J. V. y Vargas, C. (2010). Evolución y tamaño dental en poblaciones humanas de Colombia. Revista de la Academia Colombiana de Ciencias, 34(133), 423-439.

Rodríguez Saza, F. (2003). Bioarqueología molecular de la población prehispánica de la Cristalina: análisis de ADN mitocondrial a partir de restos óseos arqueológicos (Tesis de grado). Departamento de Antropología, Universidad Nacional de Colombia.

Rojas, C. (2014). Breve historia, balance y perspectivas de la bioarqueología en Colombia. En L. Luna, C. Aranda y J. Suby (Eds.), Avances recientes en la bioarqueología latinoamericana (pp. 3-33). Buenos Aires, Argentina: Grupo de Investigación en Bioarqueología (GIB).

Rojas, C. y Dotour, O. (2014). Enfermedad articular degenerativa y cambios entesiales en seis colecciones óseas prehispánicas del noroccidente de América del Sur, Chungará. Revista de Antropología Chilena, 46(1), 153-169.

Rojas, C. y Martín, J. G. (2014). Bioarqueología del bajo Magdalena, norte de Colombia, América del sur. Revista Colombiana de Antropología, 51(2), 89-120.

Salgado, H. (1989). Medio ambiente y asentamientos humanos prehispánicos en el Calima medio. Cali, Colombia: Instituto vallecaucano de Investigaciones Científicas (Inciva).

Santos, G., Monsalve, C. y Correa, L. V. (2014). Alteration of Tropical Forest Vegetation from the Pleistocene E Holocene Transition and Plant Cultivation from the End of Early Holocene Through Middle Holocene in Northwest Colombia. Quaternary International, 363, 28-42.

Saul, F. (1976). Osteography: Life History Recorded in Bone. En E. Giles y J. Friedlander (Eds.), The Measures of Man (pp. 372-382). Cambridge, Inglaterra: Cambridge University Press. 
Scheinsohn, V. (2011). Adeptos a la adaptación: tres propuestas clásicas para la arqueología y una evaluación. Antípoda, 13, 55-74.

Scott, D., Willey, P. y Connor, M. (1998). They Died with Custer: Soldier's Bones from the Battle of the Little Bighorn. Oklahoma, Estados Unidos: University Oklahoma Press.

Silva, A., Briceño, I., Burgos, J., Torres, D., Villegas, V., Gómez, A., Bernal, J. y Rodríguez, J. V. (2008). Análisis de ADN mitocondrial en una muestra de restos óseos arcaicos del periodo Herrera en la Sabana de Bogotá. Biomédica, 28(4), 569-577.

Sotomayor, H. (2007). Arqueología, arte y paleopatología en América precolombina. En H. Sotomayor y Z. Cuéllar-Montoya (Eds.), Aproximaciones a la paleopatología en América Latina (pp. 33-78). Caracas, Venezuela: Convenio Andrés Bello.

Sotomayor, H., Burgos, J. y Arango, M. (2004). Demostración de tuberculosis en una momia prehispánica colombiana por la ribotipificación del ADN de Mycobacterium tuberculosis. Biomédica, 24(1), 18-26.

Suby, J. (2012). La salud de nuestros antepasados: Una mirada sobre la paleopatología. Buenos Aires, Argentina: Laboratorio de Ecología Evolutiva Humana. Unidad de enseñanza académica Quequén. Universidad Nacional del Centro de la Provincia de Buenos Aires

Tabares, E., Rosique, J. y Delgado-Burbano, M. (2012). Tendencia de la bioantropología y un estudio de caso: su desarrollo académico en la Universidad del Cauca. Revista Colombiana de Antropología, 48(1), 259-278.

Valderrama, M. A. (2012). Una mirada a los marcadores óseos de actividad: aproximación al periodo temprano (340 a. C.-440 d. C.) del valle geográfico del río Cauca. Revista Colombiana de Antropología, 48(1), 169-187.

Van der Hammen, T. y Correal, G. (1963). Historia, clima y vegetación del Pleistoceno superior y del Holoceno de la Sabana de Bogotá. Boletín Geológico, 11(1-3), 189266.

Van der Hammen, T. y Correal, G. (1978). Prehistoric man on the Sabana de Bogotá: Data for an ecological prehistory. Palaeogeography, palaeoclimatology, palaeoecology, 25, 179-190.

Van der Hammen, T., Correal, G. y Van Klinken, G. (1990). Isótopos estables y dieta del hombre prehistórico en la sabana de Bogotá. Boletín de Arqueología, 5(2), 310.

Wade, P. (2002). Race, Nature and Culture. An Anthropological Perspective. Estados Unidos: Pluto Press.

Wood, J., Milner, G., Harpending, H. y Weiss, K. (1992). The Osteological Paradox. Problems of Inferring Prehistoric Health from Skeletal Samples. Current Anthropology, 33(4), 343-370. 